\begin{tabular}{l|l|l|l} 
&
\end{tabular}

\title{
Formação de profissional reflexivo: análise dos cursos de Design e o ENADE
}

Development of reflective practitioners: analysis of Design courses and ENADE

\author{
Cláudio Lima Ferreira, Miriam T. Lona, Vanessa Chimirra
}

design; ENADE; profissional reflexivo; educação.

O artigo apresenta e ressalta a importância de investir na formação de profissionais reflexivos com visão interdisciplinar, tendo como um dos objetivos contribuir para o melhor resultado no ENADE - Exame Nacional de Desempenho dos Estudantes. Observa-se que apesar das regulamentações do Ministério da Educação Brasileiro, ou ainda, pela exigência do atual mercado profissional, nos últimos anos, destaca-se que o profissional de Design da atualidade precisa repensar a sua atuação na sociedade de forma complexa, tendo especial atenção as questões humanísticas e sustentáveis, com vistas a proporcionar a melhoria da qualidade de vida dos seres humanos.

design; ENADE; reflective practitioners; education.

The article presents and highlights the importance of investing the development of reflective practitioners with interdisciplinary vision, as one of its objectives to contribute to the best result in ENADE - National Examination of Student Performance. It is observed that despite the regulations of the Brazilian Ministry of Education, or by the requirement of the current job market in recent years, today's design professional needs to rethink their role in the society in a complex manner, with special attention humanistic and sustainable issues, in order to provide improved quality of life for all human beings.

\section{Introdução}

Antes de questionar ou negar o ENADE como forma de avaliação do ensino superior nos cursos de design, deve-se analisar e entender como ele está estruturado e como as suas questões são formuladas. Portanto, o objetivo deste artigo não é verificar se o ENADE - Exame Nacional de Desempenho dos Estudantes é a melhor forma de se avaliar o ensino superior no Brasil, mas sim analisar e compreender os conteúdos e a estrutura das questões aplicadas nesse exame para os cursos de Design com vistas a propor estratégias que contribuam para a formação de profissionais reflexivos com visão interdisciplinar, que podem colaborar para um bom resultado no exame.

O ENADE ocorre todos os anos, entretanto é aplicado a cada três anos a cada grupo de cursos. Para os cursos de Design, houve até agora três avaliações: 2006, 2009 e 2012. No ano de 2015 será realizada a quarta avaliação dos cursos em todo Brasil.

Com vistas a compreender melhor as possíveis relações entre o ensino-aprendizagem, 0 design e as avaliações do ENADE, adotou-se neste artigo a pesquisa exploratória, pois permite

C. L. Ferreira; M. T. Lona \& V. Chimirra. 2015. Formação de profissional reflexivo: análise dos cursos de Design e o ENADE. In: C. G. Spinillo; L. M. Fadel; V. T. Souto; T. B. P. Silva \& R. J. Camara (Eds). Anais [Pôster] do 7o Congresso Internacional de Design da Informação/Proceedings [Poster] of the 7th Information Design International Conference | CIDI 2015 [Blucher Design Proceedings, num.2, vol.2]. São Paulo: Blucher, 2015. ISSN 2318-6968, DOI 10.5151/designpro-CIDI2015-cidi_198 
proporcionar maior familiaridade com o problema investigado. Quanto aos procedimentos técnicos, buscou-se a pesquisa bibliográfica, por ser desenvolvida com base em material já elaborado, constituído principalmente de livros e artigos científicos (GIL, 2008).

Por isso, foram realizadas também, análises sobre o conteúdo e as metodologias aplicados nas questões das avaliações do ENADE, visando compreender sua dinâmica sobre o ensino e aprendizagem. Nessa análise, verifica-se que grande parte das questões tem como objetivo visão projetual interdisciplinar.

\section{0 ensino-aprendizagem e a complexidade}

Ser reflexivo, criativo e colaborativo instiga dúvidas, contestações, indignações, inquietações que por muitos docentes, pesquisadores, políticos e empresários antiquados é visto como negativo. Essa análise acende uma calorosa discussão que teve início em 1984 com o lançamento do livro "Homo Academicus" por Pierre Bourdieu.

Possibilitar a formação de profissionais reflexivos, criativos e colaborativos é de suma importância para o desenvolvimento social atual, contudo, para que isso seja verdadeiramente aplicado, é preciso uma reestruturação na forma de ensinar e de aprender.

Para Luckesi et al (2001: 29), diante de um sistema educacional, como um todo, e da universidade em particular, propõe-se a reflexão na busca de entender a realidade atual da universidade. Nesse sentido, busca-se construir a universidade que, seja construtora de novos conhecimentos, e não uma mera reprodutora de informações importadas para "profissionalizar" novos quadros. A partir da mudança estrutural e da sequência de interações, o ser vivo e sua circunstância modificam-se.

Para Morin (2002), a separação resultante do processo fragmentador da simplificação e da hiperespecialização produziu a distribuição do ensino em disciplinas estanques. Uma disciplina letiva consiste em um ramo do saber voltado a si mesmo, diferente da interdisciplinaridade, que são disciplinas separadas discutindo sobre seus territórios, e a transdisciplinaridade que visa a profunda integração entre essas disciplinas pertencentes a diferentes áreas de domínio.

Em seu livro "Como Pensamos", Dewey (1959: 22), descreve o pensar reflexivo como tendo dois estados. 1- o estado de dúvida, hesitação, perplexidade, dificuldade mental, o qual origina o ato de pensar; 2- um ato de pesquisa, procura, inquirição, para encontrar material que resolva a dúvida, assente e esclareça a perplexidade.

Pensar reflexivamente possibilita o preparo e a invenção sistemáticos. É por meio do pensamento que o homem consegue aperfeiçoar e combinar sinais artificiais para indicar-lhe consequências antecipadamente, podendo consegui-las ou evitá-las.

Entretanto, para que haja a interdisciplinaridade ou a transdisciplinaridade (ou transversalidade) é necessário um pensamento organizador, que Morin (2002) chama de Pensamento Complexo ${ }^{1}$. Nos estudos realizados por ele, observa-se que o conhecimento do Pensamento Complexo não se limita à análise da ciência, mas inclui também a profundidade do conhecimento que existe nas artes, na literatura, na poesia, entre outras formas de expressão humana.

Os operadores da complexidade definidos por Morin são como os operadores de cinema, ou seja, são os operadores que põem em movimento o pensamento. Esses operadores são divididos em três:

\section{1ํ-- Operador Dialógico (e não dialético)}

\footnotetext{
${ }^{1}$ As análises do Pensamento Complexo de Edgar Morin foram analisadas com profundidade na tese de doutorado intitulada "A obra de design brasileiro dos Irmãos Campana sob o olhar das relações complexas", concluída em 2011, por Cláudio Lima Ferreira, no Instituto de Artes da UNICAMP. Esses estudos foram aplicados nesta etapa da pesquisa pósdoutoral com o objetivo de trazer novas reflexões sobre a questão do ensino e da aprendizagem nos cursos de arquitetura e urbanismo no Brasil.
} 
$2^{\circ}$ - Operador Recursivo (ou da recursividade)

3-. Operador Holograma (ou hologramático)

O primeiro operador tem como base a dialogia, que é o juntar, o entrelaçar coisas que aparentemente estão separadas. O segundo operador tem como base a recursividade, ou um circuito recursivo. Os homens aprendem no paradigma simplificador que a causa $A$ gera o efeito $B$, já na recursividade, a causa produz o efeito que, por sua vez, produz a causa. $O$ terceiro operador é o hologramático. Para esse operador, o mais importante é observar que não se consegue dissociar parte do todo, ou seja, a parte está no todo, da mesma forma que o todo está na parte.

Esses três operadores são as bases estruturadoras do Pensamento Complexo, que se organizam a partir de juntar coisas que estavam separadas; fazer circular a causa e o efeito e o efeito sobre a causa; e a ideia de totalidade.

Para o estudante, o aprendizado não se resume mais a adquirir conhecimento, mas também, poder estabelecer relações complexas quando realizar análises projetuais interdisciplinares baseando-se em exemplos práticos, de forma reflexiva, envolvendo os conceitos de totalidade e complexidade, como os estudados por Morin.

A dificuldade neste pensar em conjunto encontra-se em fazer com que instâncias separadas se comuniquem. Não se deve crer que essa comunicação acarretará a perda de sua competência, mas sim que o desenvolvimento deste pensar em conjunto, articulado a outras competências, formaria um círculo completo, reflexivo e dinâmico.

A implantação dessa nova forma de pensar, dentro dos cursos de Design no Brasil, exige planejamento e estratégias bem embasadas, porque necessitam da parceria de todos os atores que constituem a comunidade acadêmica - reitoria, diretoria, coordenação, docentes, discentes e corpo técnico administrativo. Os objetivos devem ser construídos em conjunto, e em vários níveis, para que se tenha um pertencimento de todos.

Sabe-se da dificuldade de se reestruturar novos direcionamentos e objetivos para o ensino e aprendizagem na contemporaneidade. A origem dessa dificuldade está no fato de que, desde a infância, o homem aprende que os pensamentos e as ideias deveriam ser conduzidos exclusivamente pela razão, organização e através das análises da simplificação e não da complexidade. Essa forma de organizar e direcionar o pensamento tem razões históricas e remonta à Revolução Iluminista do século XVIII, reconhecido como o século do racionalismo.

Para Morin (2003), o princípio que direcionou (e ainda direciona) o conhecimento científico de muitos estudiosos, e que se mostra ainda muito fecundo, vem apresentando graves consequências no processo de aquisição do conhecimento.

Nesse sentido, observa-se que a interdisciplinaridade, assim como a transdisciplinaridade, é a construção de um "meta" ponto de vista que não analisa apenas um assunto sobre a visão de ramo específico de um saber, mas, sim, de forma mais global, um ponto de vista abrangente sobre a vida, o conhecimento, as culturas adolescentes, as artes, a educação, entre outras. Essa é a ideia da construção dos "meta-pontos de vista". Por exemplo, o que se pode discutir, aprender e saber sobre o ensino na contemporaneidade, reunindo especialistas em ensino, em administração, em economia, em antropologia, em psicologia, em física, em matemática, em dança, em artes, além da dona de casa, do pedreiro, do lixeiro, do segurança, da merendeira, entre outros. É importante salientar que nessa visão interdisciplinar, os diferentes ramos do saber não se reúnem como uma assembleia de diferenças, mas sim como contribuições individuais de um ponto de vista includente. Esses diálogos interdisciplinares são válidos para o desenvolvimento da vida, da humanidade, da economia, da política, da educação, entre outras.

\section{Estudos práticos reflexivos e a análise do ENADE}


O Exame Nacional de Desempenho dos Estudantes - ENADE, conforme determina a Lei no 10.861/2004, é um dos procedimentos de avaliação dos cursos superiores no Brasil. Esse procedimento de avaliação tem como objetivo o acompanhamento do processo de aprendizagem e do desempenho acadêmico dos estudantes em relação aos conteúdos programáticos previstos nas diretrizes curriculares do respectivo curso de graduação.

Com base nessa avaliação dos alunos, é aplicada uma nota para cada curso, nota que vale de 1 a 5 e serve como métrica para a realização de análises e, principalmente, ações visando a melhoria da qualidade dos cursos de graduação.

As questões do ENADE, de forma geral, são formuladas a partir de quatro estruturas básicas:

Questões do tipo 1: interpretativas apoiadas em textos e conhecimentos prévios.

Questões do tipo 2: interpretativas baseadas em textos e sem conhecimento prévio

Questões do tipo 3: lógicas de causa e consequência.

Questões do tipo 4: teóricas e não baseadas em texto.

Para melhor entender cada tipo de questão que são formuladas para o ENADE dos Cursos de Design se realizou uma aprofundada análise sobre a estruturação das questões dos exames realizados em 2006, 2009 e 2012. Estas análises sobre a estrutura das questões são de suma importância para o entendimento do ENADE - Design e principalmente para evidenciar a importância da formação de um profissional reflexivo com visão interdisciplinar, que possa contribuir para um bom resultado nesse tipo de avaliação, que exigem acima de tudo reflexão e raciocínio.

Nas questões tipo 1 - interpretativas apoiadas em textos e conhecimentos prévios, se verifica, efetivamente, que é a questão mais difícil de realizar, pois exige diferentes competências. $\mathrm{Na}$ questão há um texto a ser interpretado, o que significa compreender o que o autor está afirmando ali e que será traduzido na alternativa correta com outras palavras. Observa-se que, nesses casos, não se solicita apenas entender o texto. É preciso associar conceito e texto, de modo a entender como esse conceito foi desenvolvido naquele texto especificamente.

\section{Exemplo deste tipo de questão é a 10 de 2012:}

Com a Revolução Digital do final do século XX, o campo do Design sofreu grandes transformações, expandindo-se do ponto de vista tanto de suas áreas de atuação quanto de seus métodos e procedimentos projetuais. O fato de um novo produto, processo ou serviço acomodar os propósitos comerciais do mundo globalizado, com tecnologias emergentes, bem como as implicações sociais e ambientais dele decorrentes tornaram os problemas de design mais complexos e desafiadores.

Considerando o contexto apresentado, avalie as afirmações a seguir.

I. Aos formatos tradicionais e mais lineares propostos nos primórdios da metodologia projetual vêm sendo acrescidas novas abordagens, tais como o Mind Mapping e as técnicas de Concepção de Cenários.

II. A metodologia projetual em design contempla, além de procedimentos genéricos, o emprego de procedimentos de origem profissional diferenciada e/ou correlata, o que reforça a natureza multidisciplinar do Design.

III. Os novos estudos em metodologia projetual buscam estabelecer um método de design a ser seguido que simplifique e torne o processo mais dinâmico, de modo a proporcionar melhores resultados.

É correto o que se afirma em:

A I, apenas.

B III, apenas.

C I e II, apenas.

D II e III, apenas.

E I, II e III.

Observa-se que o texto dado não explicou sobre as metodologias projetuais. Ou seja: também não basta saber o conceito, também é preciso aplicá-lo no texto que está diante do aluno. 
Nas questões do tipo 2 - interpretativas baseadas em textos - sem conhecimento prévio, se verifica que, na sua maioria, são questões que será necessário entender o que o autor quis dizer, seja a ideia central do texto, seja um aspecto que tenha sido destacado no texto e o aluno deve compreender o que o autor disse, independentemente do que acha do assunto ou sabe sobre o tema.

\section{Observa-se no exemplo da questão 11 do ENADE 2012:}

Para Paul Klee, Wassily Kandinsky e Johannes Itten, o triângulo (amarelo), o quadrado (vermelho) e o círculo (azul) serviam como uma escrita com a qual a pré-história do visível podia ser analisada, teorizada e representada. Com a assimilação de seus métodos e formas pelo ensino moderno de design, a Bauhaus tornou-se ela mesma um ponto de origem. Se Klee, Kandinsky e Itten articularam uma linguagem visual por meio de conceito de uma infância da arte, a Bauhaus tornou-se a infância do design.

LUPTON, E. \& MILLER, J. A. (orgs.). ABC da Bauhaus: a Bauhaus e a teoria do design. Tradução: André Stolarski. São Paulo: Cosac Naify, 2008 (adaptado).

Considerando o texto apresentado, verifica-se que o ponto em comum entre os três professores-artistas citados era:

A a criação de uma linguagem visual com base na arte concreta e no domínio de base teórica.

B o emprego das cores complementares e das formas tridimensionais na arte concreta em suas obras. C a aproximação, ainda que limitada, entre a capacitação técnica e a formação artística dos alunos. $\mathrm{D}$ a noção de um retorno às origens do ofício no campo do design, visando diferenciar arte e técnica. E a noção de ensino do design, que evidencia elementos básicos da arte abstrata com o emprego de cores primárias.

Nas questões do tipo 3 - lógica - causa e consequência, estruturam-se questões que podem verificar a capacidade lógica do aluno. Ou seja, o que se quer saber é a relação entre o que está afirmado em A e em B, a partir de uma lógica possível entre as duas afirmações. Assim, para poder estabelecer a relação entre as informações, precisa-se de conhecimentos prévios.

Outro ponto importante, é que por vezes, a estrutura exposta anteriormente vem associada a um texto. Nesses casos, além dos conhecimentos prévios e análise da relação entre as afirmações, o aluno precisa interpretar o texto e associá-lo a todo o resto. O que não varia muito nesse tipo de questão são as alternativas.

\section{Exemplo da questão 18 do ENADE, 2009:}

Ao desenvolver um novo produto, uma empresa depende da expertise de profissionais da engenharia, do design e do marketing.

\section{PORQUE}

Conhecimento sobre comportamento de consumidores e sobre fabricação são determinantes na definição das características do design de produtos.

A as duas afirmações são verdadeiras, e a segunda não justifica a primeira

$B$ as duas afirmações são verdadeiras, e a segunda justifica a primeira

$C$ a primeira afirmação é verdadeira, e a segunda é falsa

$\mathrm{D}$ a primeira afirmação é falsa, e a segunda é verdadeira

E as duas afirmações são falsas

Nas questões do tipo 4 o que quer que seja perguntado deve ser respondido a partir do conhecimento prévio que o aluno tem sobre o tema, a partir dos textos e explicações dadas pelo professor.

Esse tipo de questão é, em princípio, mais fácil, na medida em que não se tem que interpretar um texto. Precisa-se saber o conceito ou informação e reconhecer, em uma das alternativas, sua tradução. Se o aluno não tem o conhecimento, não há como ter certeza da resposta certa e não haverá texto que lhe auxiliará a chegar à conclusão certa, conforme observado na questão 13 do ENADE de 2012: 
Por volta de 1900, já havia se consolidado o movimento dominante da década, nascido do movimento de artes e ofícios e do movimento estético do século XIX. Seus expoentes estavam muito mais dispostos a aceitar o uso de novos materiais e a produção em massa do que os artistas do movimento de artes e ofícios. Sua característica dominante é a fluidez orgânica, inspirada pela natureza, sobretudo a vegetal. Há também referências a tradições antigas, como a arte celta e o rococó. Podia ser interpretada tanto de forma naturalística quanto abstrata, e seus princípios podiam ser aplicados a qualquer tipo de design, desde a arquitetura até a joalheria.

TAMBINI, M. O design do século. São Paulo: Ática, 1996 (adaptado).

O contexto exposto acima diz respeito a(ao):

A Art Déco.

B Art Nouveau.

C Futurismo.

D Fovismo.

E Cubismo.

Foram realizadas, também análises sobre o conteúdo e as metodologias aplicados nas questões das avaliações do ENADE, visando compreender sua dinâmica sobre o ensino e aprendizagem. Nessa análise, verifica-se que grande parte das questões tem como objetivo análises gráficas projetuais interdisciplinares. Considera-se, nesse artigo, como análises gráficas projetuais interdisciplinares as questões que envolvem uma análise reflexiva projetual de design do aluno para que se responda sobre o conteúdo de uma disciplina específica. Como, por exemplo, na figura 1:

Figura 1: questão 12 do ENADE de 2012

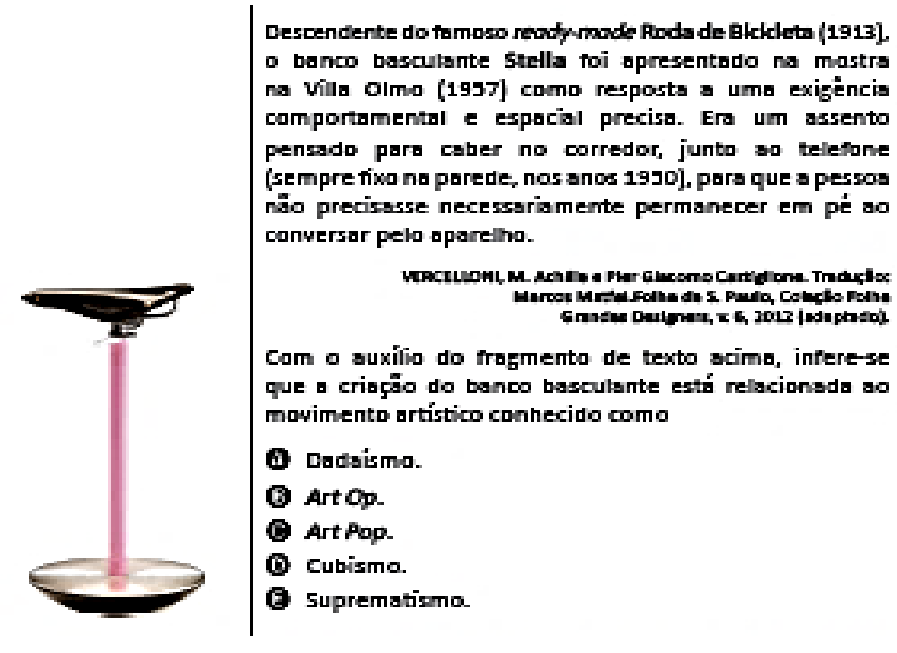

Analisando-se as questões dos ENADEs de Design, pode-se afirmar que o incentivo para os estudos práticos reflexivos envolvendo análises projetuais interdisciplinares são imprescindíveis para o bom desempenho dos alunos na avaliação.

Define-se neste artigo como Análise Projetual Interdisciplinar ${ }^{2}$, as análises sobre um projeto de design que necessitem de conhecimento e raciocínio interdisciplinar para que se possa responder a questão apresentada. Para essa análise, é importante que o aluno saiba interrelacionar os conteúdos das disciplinas do curso de design para a resolução de um problema.

O que na maioria das vezes é solicitado são análises de referências projetuais usadas como base para o desenvolvimento do projeto de design a ser realizado. Sabe-se que um dos instrumentos de trabalho para a atividade projetual de design é o "repertório", ou seja, o

\footnotetext{
${ }^{2}$ Análise Projetual Interdisciplinar foi discutida no pós-doutorado do pesquisador Claudio Lima Ferreira, na Faculdade de Arquitetura e Urbanismo da Universidade Presbiteriana Mackenzie, 2014.
} 
conhecimento de determinado universo de realização, enquanto conjunto de elementos metodicamente dispostos, e que devem estar processados pelo crivo crítico do profissional.

A atividade projetual depende do domínio, pelo profissional, de repertório consistente e crítico, processando-se em grande parte pela adaptação de precedentes. $O$ ensino de design, por sua vez, trabalha com repertórios (de conhecimentos culturais, estéticos, técnicos) e com a estruturação de sua constituição, e esse tem sido um problema constantemente identificado e apontado no ensino de projeto.

Entender a importância das análises projetuais interdisciplinares para o bom desempenho dos estudantes no Exame Nacional de Desempenho do Estudante de Design é fundamental para repensar o futuro do nosso ensino e aprendizado. É importante evidenciar as vantagens da inclusão de estratégias metodológicas que contribuam para a formação de profissionais reflexivos e colaborativos; demonstrando que esta formação pode contribuir para o bom desempenho dos estudantes no ENADE, assim como em qualquer outro exame de concurso.

A partir das análises das questões que formam as avaliações ENADE para os cursos de Design, verificou-se que 55\% das questões da avaliação 2006, 40\% da avaliação de 2009 e 60\% da avaliação de 2012 possuem análises projetuais interdisciplinares, ou seja, para que o aluno responda uma questão sobre um determinado conteúdo específico, é necessária uma análise interdisciplinar envolvendo conhecimentos projetuais de design. Se o aluno não tiver conhecimentos projetuais reflexivos interdisciplinares, terá possivelmente dificuldade para responder sobre o assunto específico solicitado.

\section{Considerações finais}

Mesmo as análises de conteúdo das avaliações ENADE não sendo nosso principal objetivo nesta pesquisa, são de suma importância para a identificação das questões reflexivas exigidas neste tipo de avaliação, enfatizando as análises projetuais interdisciplinares.

Nesse sentido as Instituições de Ensino Superior devem repensar a sua forma de ensinar nos cursos de Design e buscar consolidar as disciplinas de projeto, como disciplinas guia para o curso. São estas disciplinas que contribuirão efetivamente para as relações interdisciplinares e auxiliarão na formação de profissionais reflexivos e colaborativos. É importante salientar que a instrução buscando a reflexão é uma das formas de preparar seus alunos para melhores resultados nas avaliações externas para o curso e Instituição.

Para Verhine (2006), o ENADE, além de seu inegável interesse como maneira de avaliar o desempenho dos cursos que preparam os profissionais para sua atuação na sociedade, indica rumos para o ensino ministrado nas escolas de ensino superior, dando ênfase em determinados assuntos e privilegiando formas de expor o conhecimento adquirido ao longo do processo de aprendizado.

As universidades, por sua vez, buscam orientar suas atividades de ensino de forma a obter melhores resultados neste processo de avaliação e dessa maneira direcionam seus cursos no sentido de alcançar metas cada vez mais acima dos resultados anteriores. As diretrizes adotadas pelo ENADE, em todos os seus aspectos, e não apenas naquele aqui abordado, têm consequências indiscutíveis na formação dos futuros profissionais e, como tal, no seu desempenho face ao seu papel na sociedade.

\section{Referências}

DEWEY, J. Democracia e Educação: Introdução a Filosofia da Educação. São Paulo: Companhia Editora Nacional, 1959.

FERREIRA, C.L. Formando profissionais reflexivos, criativos e colaborativos: o ensino de 
Arquitetura e Urbanismo no Brasil, Pesquisa de Pós-Doutorado, Universidade Presbiteriana Mackenzie, São Paulo, 2014.

FERREIRA, C.L. A obra de design brasileiro dos Irmãos Campana sob o olhar das Relações Complexas, Tese de Doutorado, Instituto de Artes-UNICAMP, Campinas, 2011

GIL, A. C. Como elaborar projetos de pesquisa. 4. ed. São Paulo: Atlas, 2008.

LUCKESI, C; BARRETO, E.; COSMA, J.; BAPTISTA N. Fazer Universidade: Uma proposta metodológica. São Paulo: Editora Cortez, 2001.

MORIN, E. Reformar o Pensamento. Lisboa: Instituto Piaget, 2002. Os Sete Saberes Necessários à Educação do Futuro. São Paulo: Cortez, 2003.

VERHINE, R. E., DANTAS, L. M. V., SOARES, J. F. Do Provão ao ENADE: uma análise comparativa dos exames nacionais utilizados no Ensino Superior Brasileiro. v.14, № 52, p. 291-310. Ensaio: Aval. Pol. Publ. Educ., Rio de Janeiro, 2006.

\section{Sobre os autores}

Dr. Cláudio Lima Ferreira, Universidade Anhembi Morumbi, Brasil: claudiol.f@uol.com.br Ms. Miriam T. Lona, Universidade Anhembi Morumbi, Brasil: miriam.lona@anhembimorumbi.edu.br

Ms. Vanessa Chimirra, Universidade Anhembi Morumbi, Brasil: vchimirra@anhembi.br 